\title{
A Novel Integrating Virtual Reality Approach for the Assessment of the Attachment Behavioral System
}

\author{
Irene Alice Chicchi Giglioli 1*, Gabriella Pravettoni2,3, Delores Lucia Sutil Martín ${ }^{4}$, \\ Elena Parra ${ }^{1}$ and Mariano A. Raya ${ }^{1}$ \\ ${ }^{1}$ Instituto de Investigación e Innovación en Bioingeniería (i3B), Universitat Politécnica de Valencia, Valencia, Spain, \\ ${ }^{2}$ Department of Oncology and Hemato-Oncology (DIPO), University of Milan, Milan, Italy, ${ }^{3}$ Applied Research Division for \\ Cognitive and Psychological Science, European Institute of Oncology, Milan, Italy, ${ }^{4}$ Departamento de Economía de la \\ Empresa, Facultad de Ciencias Sociales y Jurídicas, Universidad Rey Juan Carlos, Madrid, Spain
}

Virtual reality (VR) technology represents a novel and powerful tool for behavioral research in psychological assessment. VR provides simulated experiences able to create the sensation of undergoing real situations. Users become active participants in the virtual environment seeing, hearing, feeling, and actuating as if they were in the real world. Currently, the most psychological VR applications concern the treatment of various mental disorders but not the assessment, that it is mainly based on paper and pencil tests. The observation of behaviors is costly, labor-intensive, and it is hard to create social situations in laboratory settings, even if the observation of actual behaviors could be particularly informative. In this framework, social stressful experiences can activate various behaviors of attachment for a significant person that can help to control and soothe them to promote individual's well-being. Social support seeking, physical proximity, and positive and negative behaviors represent the main attachment behaviors that people can carry out during experiences of distress. We proposed VR as a novel integrating approach to measure real attachment behaviors. The first studies on attachment behavioral system by VR showed the potentiality of this approach. To improve the assessment during the VR experience, we proposed virtual stealth assessment (VSA) as a new method. VSA could represent a valid and novel technique to measure various psychological attributes in real-time during the virtual experience. The possible use of this method in psychology could be to generate a more complete, exhaustive, and accurate individual's psychological evaluation.

Keywords: attachment, virtual reality, presence, ecological validity, stealth assessment, evidence-centered design

\section{INTRODUCTION}

During experiences of distress, people of all ages can carry out various behaviors, such as social support seeking, physical proximity, and positive and negative behaviors. Experiences of loneliness, separation, threat, and loss can activate interpersonal behaviors of attachment for a significant person that can help to control and soothe them to promote individual's well-being (Schmidt et al., 2002, 2003; Maunder et al., 2005, 2006; Ditzen et al., 2008).

Attachment paradigm represents one of the models that attempted to explain the formation of social and close relationship patterns. According to Bowlby (1969) the quality of the first parent-child interactions shape the cognitive and emotional representations that will later drive 
the self and other's perceptions, and new relationships (Bowlby, 1969, 2005; Main et al., 1985; Ainsworth et al., 2015). In attachment research, the assessment methods widely used and validated are self-report questionnaires, interviews or projective measures (see the review of Ravitz et al., 2010), while attachment behaviors have been addressed less in adults. The observation of attachment behaviors is costly, labor-intensive, and it is hard to create social situations in laboratory settings, however, observation of actual attachment behaviors could be particularly informative.

In the current article, we suggest virtual reality (VR) as a novel integrating approach to elicit attachment behavioral system, as well as a powerful tool to bridge the gap among realism, dynamics of social interactions and experimental control. Indeed, VR can generate real-life simulated situations, including many sensory simulators, such as stereo headphones, olfactory and haptic devices, which can create real immersive world experiences. Furthermore, VR can provide several advantages in the assessment of attachment behavioral system. First, VR can create various stimuli, which can target specific aspects of attachment system (e.g., support seeking, physical proximity, positive and negative behaviors). Second, VR can be used to track behavioral and physiological responses, allowing an integrated assessment of the attachment experiences. Within the VR approach, we suggest stealth assessment as new method for assessing the attachment behavioral system since it can incorporate assessment of multi-attachment behaviors in real time during the virtual experience.

\section{VIRTUAL REALITY AS A NOVEL INTEGRATING TOOL FOR ASSESSING}

Virtual reality can be defined as a simulated experience formed by a synthetic computer-based environment, able to create the sensation of undergoing real experiences. Users become active participants and interact with the virtual situations and other virtual agents, seeing, hearing, and feeling the experience as if they were acting in the real world (Wilson, 2002; Shapiro, 2007).

Until now, VR has showed its efficacy in clinical psychology, neuropsychology, and in cognitive and motor rehabilitation (Llorens et al., 2014, 2016; Borrego et al., 2016). In clinical psychology, VR has been especially applied for the treatment of different anxiety disorders (e.g., phobias) (Botella et al., 2006; Wrzesien et al., 2014), mood disorders (Baños et al., 2006; Meyerbröker and Emmelkamp, 2010), post-traumatic stress disorder (PTSD) (Rothbaum et al., 2001; Cárdenas-López and Rosa-Gómez, 2011; Cárdenas and De La Rosa, 2012), and body image disturbances in patients with eating disorders (Riva et al., 2001, 2016; Gorini et al., 2010; Ferrer-García and Gutiérrez-Maldonado, 2012; Dakanalis et al., 2016). In VR clinical treatments, patients are exposed to fear situations or specific traumatic events to gradually face in a safe and controlled environment. Recently, VR has become an important tool for simulating real world events, allowing moving the subject to a virtual world where any kind of stimulus is possible. Furthermore, VR treatments rely on previous assessments that inform diagnosis. Usually, the assessment uses paper and pencil tests, providing people's conscious answers and attitudes about themselves and others at a given time.

Even if this assessment approach provides highly systematic validity and reliability, they present some limitations in terms of detecting the unware responses, as well as in creating and experiencing real situations able to activate specific behaviors related to the construct that we want to assess. Furthermore, they have also been criticized as limited in the ecological validity, referring to the degree of correspondence that a test has relative to the real world or real behaviors in context or situation.

In this framework, VR could advocate as a powerful assessing tool to improve ecological validity, maintaining experimental control, and to approach research themes that could be answered together with the traditional method, thanks to the technical capacity needed to approach behavioral topics.

In the next paragraph, we deepen the main features of VR to elicit a stronger and more real experience and to obtain reliable measurements of human behavior.

\section{Virtual Reality Features}

Immersion, interactivity, realism, and transference represent the most features of VR experiences (Biocca, 1997; Lombard and Ditton, 1997; Loomis et al., 1999; Heeter, 2000; Biocca et al., 2001; Bailenson et al., 2006; Saribay and Andersen, 2007; Skalski and Tamborini, 2007; Andersen and Thorpe, 2009; Slater, 2009; Sundar et al., 2010; Cummings and Bailenson, 2016). Immersion can be described as a technological feature based on various input and output devices able to produce sensory and perceptual information that create the illusion of being in the physical world (Slater, 2009). The combination of more sensory and perceptual information with stereoscopic visual input (e.g., Head Mounted Display - HMD), audio and tactile input, can augment the level of immersion, generating depth and perception of realism (Loomis et al., 1999; Cummings and Bailenson, 2016). In literature, higher level of immersion, compared to lower (e.g., desktop computer) reported significant results in terms of explorative tasks (Boyd, 1997; Sandstrom et al., 1998), distance estimation and depth perception (Heineken and Schulte, 2001), cooperative tasks (Roberts et al., 2005), and short-term spatial memory (Adamo-Villani and Johnson, 2010; Bailey et al., 2012). Interactivity can be defined as the perception process in which user can interact with virtual contents and agents, in which the virtual contents and agents respond to the user's actions in real-time, providing high level of engagement and realism (Lombard and Ditton, 1997; Heeter, 2000; Biocca et al., 2001; Skalski and Tamborini, 2007; Sundar et al., 2010). Furthermore, as mentioned VR allows social interactions among two or more virtual or real agents through verbal or written information, such as voice or video recordings, human actors, and vignettes, and non-verbal behaviors, such as mutual gaze or interpersonal distance. Studies on the effectiveness of social interactions in VR showed that people transfer their emotions behaviors, and expectations of past 
relationship to new relationships, specifically to virtual agents (Sanchez-Vives and Slater, 2005; Bailenson et al., 2006; Yee and Bailenson, 2007; Schönbrodt and Asendorpf, 2010, 2011). More in detail, Schönbrodt and Asendorpf (2010) examined the correlation between the behaviors for a virtual partner and real-life relationships measuring variables as interpersonal motives and relationship satisfaction. Results showed that participants transferred their emotional and behavioral patterns to the virtual partner as if he/she was the real partner. At the same time, those were dissatisfying with their real relationship, initially, projected their negative expectations on the virtual character, and during the game tried to re-establish close and positive interactions.

These features can create the sensation of presence, the subjective psychological state of "being there" in the virtual world leaving the perception of technological mediation behind (Biocca, 1997; Lombard and Ditton, 1997; Persky and Blascovich, 2008).

Finally, VR can create any kind of stimulus, also reproducing the same stimuli infinite times, allowing an extensive control over the measurement validity.

\section{Behavioral and Physiological Measures in Virtual Reality}

Virtual reality can also integrate behavioral and physiological measures for tracking users' responses. Indeed, VR allows measuring users' behavior during the experience, using motion-tracking device systems, such as eye tracking devices, or head-movement devices. These devices can track head-movements and eye-movements, allowing the analysis of non-verbal displays of attachment. In addition, inside a virtual environment, physiological measures can be monitored by wearable device. Heart rate variability, skin conductance, and skin temperature can also be tracked during the virtual experience, providing continuous and real-time data. Therefore, VR can be seen as an integrated measurement tool providing more ecological and controlled setting able to develop a more holistic and comprehensive psychological model of the experiences (Loomis et al., 1999; Tarr and Warren, 2002; Bohil et al., 2011; Parsons, 2015; Fusaro et al., 2016).

\section{APPLYING VIRTUAL REALITY FOR ASSESSING ATTACHMENT BEHAVIORAL SYSTEM}

\section{Attachment Theory}

Attachment theory is a composite psychosocial development theory that explains the formation of interpersonal relationships patterns. Bowlby (1969) theorized that children have a natural predisposition to develop a bond of attachment to a significant other, the attachment figure, especially in stressful situations. During these experiences, children aim to seek and maintain proximity to the attachment figure, looking for support and safety (Bowlby, 1969). If the attachment figure gives attentive and positive emotional responsiveness, the child will build positive mental representations of self and others (Gunnar et al., 1996) and vice-versa. The positive or negative mental representations formed internal working models (IWMs) about self, others, and relationships, allowing later to regulate behaviors based on formed expectations. In this framework, several longitudinal studies have shown that the IWMs remain quite stable during the lifespan (Stern, 1985; Tronick and Gianino, 1986; Beebe and Lachmann, 1994; Beebe et al., 1997; Hamilton, 2000; Waters et al., 2000; Steele et al., 2003; Weinfield et al., 2004; Sroufe, 2005). In this framework, a longitudinal study of Sroufe et al. (2009) has showed a continuity and stability over the time among the attachment behaviors. More in detail, children with positive mental representations will be adults able to react to stressful events with lower levels of distress and are more likely to cope with stress by seeking support, hold positive expectations about relationships. Instead, children with negative mental representations will be adults that can tend, on one hand, to perceive others as unresponsive or inconsistent, worry about being rejected, showing hyper-activation strategies and hypervigilance (Main, 1990; Collins et al., 2006; Ainsworth et al., 2015). Hyper-activation strategies demand proximity and care from attachment figures (Mikulincer et al., 2003) including hypervigilance toward attachment cues, use of worry, and rumination (Cassidy, 1994). These strategies often fail and can amplify distress (Mikulincer and Shaver, 2007). On other hand, individuals with negative mental representations can prefer being distant and detached from others, report no need for close relationships, and tend to distrust affective signals from others (Cassidy and Kobak, 1988; Mikulincer et al., 2003).

\section{Research on Virtual Reality for Assessing Attachment Behavioral System}

To date, three studies have investigated the attachment behavioral system in close relationships using virtual environments (Kane et al., 2012; Schönbrodt and Asendorpf, 2012; Symons et al., 2015). In the first study, Schönbrodt and Asendorpf (2012) created a 2D online computer game (Simoland), for investigating attachment behaviors toward a virtual partner during attachment-related experiences (separation, conflict, and threat). Technologically, Simoland used a low-cost and open environment with non-immersive graphical representation in which the characters were depicted by simple beings able to interact each other by vignettes. The participant could direct the behaviors (physical distance, support seeking, positive and negative behaviors) of one virtual character. Furthermore, during the game, the participant attributed the emotions of the virtual character. Results showed significant correlation between the participant attachment style and virtual character behaviors across the three conditions. More in detail, across the three conditions, anxious participants showed more negative emotional behaviors and responses, looking for more physical proximity and support seeking than avoidant participants that, they acted by using more deactivating strategies.

In the second study, Kane et al. (2012), using a 3D-immersive VR environment, hypothesized that the presence of a partner was not enough for providing individual's safety. They created 
a canyon path in which participants had to walk, seeing or not seeing at the end of the path their virtual partner. The authors compared three conditions: in the first condition participants should walk alone for the canyon; in the second condition the virtual partner at the end of the path was bodily oriented to the participant; in the third condition, the virtual partner was not oriented to the participant. Results showed that participants in the second condition perceived the walking task as less stressful than those who were alone and more secure than those in the third condition. Furthermore, participants in the third condition showed later less physical proximity from their partner.

The third and more recent study (Symons et al., 2015) examined relationship between adult attachment styles and caregiver attitudes toward a virtual personalized child, raised in a simulated parenting environment from birth to 19 years. The results showed that avoidance and anxiety attachment styles were negatively related to caregiver attitudes. More in detail, dismissing and preoccupied adults showed less positive attitudes toward a child and felt less willingness as an attachment figure to their child.

These three studies, even if considered different aspects of the attachment system, they used a novel methodology: the simulated VR experience, showing significant results consistent with the previous studies that used traditional methods of assessing (Ainsworth, 1978; Mikulincer and Shaver, 2005). However, these studies showed how the attachment paradigm is a broad and complex construct, consisting of multi-aspects. Indeed, if Schönbrodt and Asendorpf (2011) have correlated behavioral measures, such as interactional actions (positive vs. negative), emotional attribution, and physical distance with attachment and emotional scales, Kane et al. (2012) have correlated ad hoc measures about stress appraisal, emotional security, and perceived responsiveness of self, while Symons et al. (2015) utilized measures about caregiver attitudes, secure scale, and trait anxiety questionnaires. Interesting and novel behavioral measures have been introduced by Kane et al. (2012). More in detail, vigilance and interpersonal distancing behaviors have been measured to obtain more accurate implicit measures of social approach/avoidance. As noted above, the possibility to introduce behavioral measures for the assessment of the attachment system can represent a potential of VR together with the traditional methods.

\section{Virtual Stealth Assessment Method for Assessing Attachment Behavioral System}

Virtual stealth assessment (VSA) can be defined as a new real-time performance-based assessment that allows assessing individuals' attributes (Shute, 2009). SA, introduced in virtual learning games, allows directly and invisibly assessing various behaviors related to attributes while users play, correlating them to traditional assessment (pre-and posttests) (Shute and Ke, 2012). The development of a VSA is based on evidencecentered design (ECD), characterized by three models of reference: the competence model is based on the recognition of which attributes we want to assess, the structural model in which the behaviors that could reveal the attributes are identified, and the task model in which are developed tasks that could elicit those behaviors previously described Mislevy et al. (2003). An example of stealth assessment can be represented by Newton's Playground, a 2D computergame, constituted by 74 problems of increasing difficulty, which aim for the user was to lead a green ball to a red ball for blowing up it. To move the ball, the users had to draw or create inclined ramps, pendulums, levers, and springboards, according to the rules of Newton's gravity. The game assessed three competencies: creativity, conscientiousness, and conceptual physics understanding (Shute et al., 2013). For example, according to the literature, consciousness is formed by several facets, such as persistence, perfectionism, organization, and carefulness. For each component various behaviors are identified with the relative development of the tasks or problems for solving. As in Newton's Playground, we propose the implementation of VSA for the evaluation of the attachment behavioral system. The focus will be on assessing behavioral aspects related to attachment, such as physical distance, support seeking, positive and negative behaviors in stressful and non-stressful situations. The development of VSA will be based on creating an immersive social videogame, involving five conditions, that they will include stressful social simulated experiences of loneliness, separation, threat, and loss, more non-stressful social situations. For each situation, several social interaction decisions making and problem solving tasks will be implement in the virtual environment in order to assess the behaviors mentioned above. In accordance with ECD, the assessment will be woven into the environment and invisible to user, encouraging the elicitation of real behaviors, for later correlating outcome behaviors with the traditional attachment questionnaires. VSA would provide a new method of assessment that, integrated with the traditional paper and pencil tests, could enrich assessment.

\section{CONCLUSION}

The attachment system is a composite paradigm for understanding relationship processes, traditionally assessed by valid and reliable interview, projective, or self-report measures (Ravitz et al., 2010), but with a limited ecological validity in the assessment of real attachment behaviors. VR and SA provide a new approach and method to measure them in real-time, allowing to simulate various attachment situations, maintaining high levels of experimental control and ecological validity. Several studies support VR as a treatment technology (Baños et al., 2006; Meyerbröker and Emmelkamp, 2010; Cárdenas-López and Rosa-Gómez, 2011; Wrzesien et al., 2014; Riva et al., 2016) but not for the assessment, mainly based on paper and pencil tests. SA will allow for a multi-level assessment of attachment that could be useful to catch real behaviors during the virtual experience (Shute, 2009). Finally, the possible use of this method in psychology could be to generate 
a more complete, exhaustive, and accurate individual's psychological evaluation.

\section{AUTHOR CONTRIBUTIONS}

All authors have significantly contributed to the manuscript according to the specific scientific competences. MR and IC made substantial contributions to manuscript conception. IC participated in drafting the manuscript, while DS, GP, and EP revised it critically for important intellectual content. MR and GP supervised the entire work. All authors give final approval of the version to be submitted and any revised version.

\section{REFERENCES}

Adamo-Villani, N., and Johnson, E. (2010). "Virtual heritage applications: the 3D tour of MSHHD," in Proceedings of the ICCSIT 2010-International Conference on Computer Science and Information Technology, Rome.

Ainsworth, M. D. S. (1978). The Bowlby-Ainsworth attachment theory. Behav. Brain Sci. 1, 436-438. doi: 10.1017/S0140525X00075828

Ainsworth, M. D. S., Blehar, M. C., Waters, E., and Wall, S. N. (2015). Patterns of Attachment: A Psychological Study of the Strange Situation. Hove: Psychology Press.

Andersen, S. M., and Thorpe, J. S. (2009). An IF-THEN theory of personality: significant others and the relational self. J. Res. Pers. 43, 163-170. doi: 10.1016/ j.jrp.2008.12.040

Bailenson, J. N., Yee, N., Merget, D., and Schroeder, R. (2006). The effect of behavioral realism and form realism of real-time avatar faces on verbal disclosure, nonverbal disclosure, emotion recognition, and copresence in dyadic interaction. Presence 15, 359-372. doi: 10.1162/pres.15. 4.359

Bailey, J., Bailenson, J. N., Won, A. S., Flora, J., and Armel, K. C. (2012). "Presence and memory: immersive virtual reality effects on cued recall," in Proceedings of the International Society for Presence Research Annual Conference, Philadelphia, PA, 24-26.

Baños, R. M., Liaño, V., Botella, C., Alcañiz, M., Guerrero, B., and Rey, B. (2006). "Changing induced moods via virtual reality," in Proceedings of the International Conference on Persuasive Technology (Berlin: Springer), 7-15.

Beebe, B., Lachmann, F., and Jaffe, J. (1997). Mother-Infant interaction structures and presymbolic self-and object representations. Psychoanal. Dialogues 7 , 133-182. doi: 10.1080/10481889709539172

Beebe, B., and Lachmann, F. M. (1994). Representation and internalization in infancy: three principles of salience. Psychoanal. Psychol. 11, 127-165. doi: $10.1037 / \mathrm{h} 0079530$

Biocca, F. (1997). The cyborg's dilemma: progressive embodiment in virtual environments. J. Comput. Mediat. Commun. 3. doi: 10.1111/j.1083-6101.1997. tb00070.x

Biocca, F., Harms, C., and Gregg, J. (2001). “The networked minds measure of social presence: pilot test of the factor structure and concurrent validity," in Proceedings of the 4th Annual International Workshop on Presence, Philadelphia, PA, 1-9.

Bohil, C. J., Alicea, B., and Biocca, F. A. (2011). Virtual reality in neuroscience research and therapy. Nat. Rev. Neurosci. 12, 752-762. doi: 10.1038/nrn3122

Borrego, A., Latorre, J., Llorens, R., Alcañiz, M., and Noé, E. (2016). Feasibility of a walking virtual reality system for rehabilitation: objective and subjective parameters. J. Neuroeng. Rehabil. 13, 68. doi: 10.1186/s12984-0160174-1

Botella, C., Baños, R. M., Guerrero, B., García-Palacios, A., Quero, S., and Raya, M. A. (2006). Using a flexible virtual environment for treating a storm phobia. Psychnol. J. 4, 129-144.

Bowlby, J. (1969). Attachment and Loss: Attachment, Vol. 1. New York, NY: Basic Books.

Bowlby, J. (2005). A Secure Base: Clinical Applications of Attachment Theory, Vol. 393. Abingdon: Taylor \& Francis.

\section{FUNDING}

This work was supported by the Spanish Ministry of Economy, Industry and Competitiveness funded project "Advanced Therapeutically Tools for Mental Health” (DPI2016-77396-R).

\section{ACKNOWLEDGMENT}

The work has been promoted by the call for support for mobility 2016 within the Program for Training Researchers of the Universitat Politecnica de Valencia.

Boyd, C. (1997). "Does immersion make a virtual environment more usable?", in Proceedings of the CHI'97 Extended Abstracts on Human Factors in Computing Systems (New York, NY: ACM), 325-326. doi: 10.1145/1120212.1120416

Cárdenas, G., and De La Rosa, A. (2012). Using virtual reality for PTSD treatment in criminal violence victims. J. Cyberther. Rehabil. 5, 65-67.

Cárdenas-López, G., and Rosa-Gómez, A. D. L. (2011). Post-traumatic stress disorder treatment with virtual reality exposure for criminal violence: a case study in assault with violence. Int. J. Disabil. Hum. Dev. 10, 379-383. doi: 10.1515/IJDHD.2011.061

Cassidy, J. (1994). Emotion regulation: influences of attachment relationships. Monogr. Soc. Res. Child Dev. 59, 228-249. doi: 10.2307/1166148

Cassidy, J., and Kobak, R. R. (1988). Avoidance and its relation to other defensive processes. Clin. Implic. Attach. 1, 300-323. doi: 10.1037/a0031798

Collins, N. L., Ford, M. B., Guichard, A. C., and Allard, L. M. (2006). Working models of attachment and attribution processes in intimate relationships. Pers. Soc. Psychol. Bull. 32, 201-219. doi: 10.1177/0146167205280907

Cummings, J. J., and Bailenson, J. N. (2016). How immersive is enough? A metaanalysis of the effect of immersive technology on user presence. Media Psychol. 19, 272-309. doi: 10.1080/15213269.2015.1015740

Dakanalis, A., Gaudio, S., Serino, S., Clerici, M., Carrà, G., and Riva, G. (2016). Body-image distortion in anorexia nervosa. Nat. Rev. Dis. Primers 2, 16026. doi: 10.1038/nrdp.2016.26

Ditzen, B., Schmidt, S., Strauss, B., Nater, U. M., Ehlert, U., and Heinrichs, M. (2008). Adult attachment and social support interact to reduce psychological but not cortisol responses to stress. J. Psychosom. Res. 64, 479-486. doi: 10.1016/ j.jpsychores.2007.11.011

Ferrer-García, M., and Gutiérrez-Maldonado, J. (2012). The use of virtual reality in the study, assessment, and treatment of body image in eating disorders and nonclinical samples: a review of the literature. Body Image 9, 1-11. doi: 10.1016/j.bodyim.2011.10.001

Fusaro, M., Tieri, G., and Aglioti, S. M. (2016). Seeing pain and pleasure on self and others: behavioral and psychophysiological reactivity in immersive virtual reality. J. Neurophysiol. 116, 2656-2662. doi: 10.1152/jn.00489.2016

Gorini, A., Griez, E., Petrova, A., and Riva, G. (2010). Assessment of the emotional responses produced by exposure to real food, virtual food and photographs of food in patients affected by eating disorders. Ann. Gen. Psychiatry 9:30. doi: 10.1186/1744-859X-9-30

Gunnar, M. R., Brodersen, L., Nachmias, M., Buss, K., and Rigatuso, J. (1996). Stress reactivity and attachment security. Dev. Psychobiol. 29, 191-204. doi: 10.1002/(SICI)1098-2302(199604)29:3<191::AID-DEV1>3.0.CO;2-M

Hamilton, C. E. (2000). Continuity and discontinuity of attachment from infancy through adolescence. Child Dev. 71, 690-694. doi: 10.1111/1467-8624.00177

Heeter, C. (2000). Interactivity in the context of designed experiences. J. Interact. Advert. 1, 3-14. doi: 10.1080/15252019.2000.10722040

Heineken, E., and Schulte, F. P. (2001). Acquiring Distance Knowledge in Virtual Environments. Duisburg: Gerhard Mercator University.

Kane, H. S., McCall, C., Collins, N. L., and Blascovich, J. (2012). Mere presence is not enough: responsive support in a virtual world. J. Exp. Soc. Psychol. 48, 37-44. doi: 10.1016/j.jesp.2011.07.001

Llorens, R., Navarro, M. D., Noé, E., and Alcañiz, M. (2016). “Competition improves attention and motivation after stroke," in Proceedings of the 
11th International Conference on Disability, Virtual Reality and Associated Technologies, Los Angeles, CA, 31-39.

Llorens, R., Noé, E., Ferri, J., and Alcañiz, M. (2014). Virtual reality-based telerehabilitation program for balance recovery. A pilot study in hemiparetic individuals with acquired brain injury. Brain Inj. 28, 169.

Lombard, M., and Ditton, T. (1997). At the heart of it all: the concept of presence. J. Comput. Mediat. Commun. 3. doi: 10.1111/j.1083-6101.1997.tb 00072.x

Loomis, J. M., Blascovich, J. J., and Beall, A. C. (1999). Immersive virtual environment technology as a basic research tool in psychology. Behav. Res. Methods Instrum. Comput. 31, 557-564. doi: 10.3758/BF03200735

Main, M. (1990). Cross-cultural studies of attachment organization: recent studies, changing methodologies, and the concept of conditional strategies. Hum. Dev. 33, 48-61. doi: 10.1159/000276502

Main, M., Kaplan, N., and Cassidy, J. (1985). Security in infancy, childhood, and adulthood: a move to the level of representation. Monogr. Soc. Res. Child Dev. 66-104. doi: 10.2307/3333827

Maunder, R. G., Lancee, W. J., Hunter, J. J., Greenberg, G. R., and Steinhart, A. H. (2005). Attachment insecurity moderates the relationship between disease activity and depressive symptoms in ulcerative colitis. Inflamm. Bowel Dis. 11, 919-926. doi: 10.1097/01.mib.0000179468.78876.2d

Maunder, R. G., Lancee, W. J., Nolan, R. P., Hunter, J. J., and Tannenbaum, D. W. (2006). The relationship of attachment insecurity to subjective stress and autonomic function during standardized acute stress in healthy adults. J. Psychosom. Res. 60, 283-290. doi: 10.1016/j.jpsychores.2005. 08.013

Meyerbröker, K., and Emmelkamp, P. M. (2010). Virtual reality exposure therapy in anxiety disorders: a systematic review of process-and-outcome studies. Depress. Anxiety 27, 933-944. doi: 10.1002/da.20734

Mikulincer, M., and Shaver, P. R. (2005). Attachment theory and emotions in close relationships: exploring the attachment-related dynamics of emotional reactions to relational events. Pers. Relationsh. 12, 149-168. doi: 10.1111/j.13504126.2005.00108.x

Mikulincer, M., and Shaver, P. R. (2007). Attachment in Adulthood: Structure, Dynamics, and Change. New York, NY: Guilford Press.

Mikulincer, M., Shaver, P. R., and Pereg, D. (2003). Attachment theory and affect regulation: the dynamics, development, and cognitive consequences of attachment-related strategies. Motiv. Emot. 27, 77-102. doi: 10.1023/A: 1024515519160

Mislevy, R. J., Almond, R. G., and Lukas, J. F. (2003). A Brief Introduction to Evidence-Centered Design. Princeton, NJ: Educational Testing Service.

Parsons, T. D. (2015). Virtual reality for enhanced ecological validity and experimental control in the clinical, affective and social neurosciences. Front. Hum. Neurosci. 9:660. doi: 10.3389/fnhum.2015.00660

Persky, S., and Blascovich, J. (2008). Immersive virtual video game play and presence: influences on aggressive feelings and behavior. Presence 17, 57-72. doi: $10.1162 /$ pres.17.1.57

Ravitz, P., Maunder, R., Hunter, J., Sthankiya, B., and Lancee, W. (2010). Adult attachment measures: a 25-year review. J. Psychosom. Res. 69, 419-432. doi: 10.1016/j.jpsychores.2009.08.006

Riva, G., Bacchetta, M., Baruffi, M., and Molinari, E. (2001). Virtual realitybased multidimensional therapy for the treatment of body image disturbances in obesity: a controlled study. Cyberpsychol. Behav. 4, 511-526. doi: 10.1089/ 109493101750527079

Riva, G., Gutiérrez-Maldonado, J., and Wiederhold, B. K. (2016). Virtual worlds versus real body: virtual reality meets eating and weight disorders. Cyberpsychol. Behav. Soc. Netw. 19, 63-66. doi: 10.1089/cyber.2016. 29025.gri

Roberts, D. J., Wolff, R., and Otto, O. (2005). Supporting a closely coupled task between a distributed team: using immersive virtual reality technology. Comp. Inform. 24, 7-29.

Rothbaum, B. O., Hodges, L. F., Ready, D., Graap, K., and Alarcon, R. D. (2001). Virtual reality exposure therapy for Vietnam veterans with posttraumatic stress disorder. J. Clin. Psychiatry 62, 617-622. doi: 10.4088/JCP.v62 n0808

Sanchez-Vives, M. V., and Slater, M. (2005). From presence to consciousness through virtual reality. Nat. Rev. Neurosci. 6, 332-339. doi: 10.1038/nrn 1651
Sandstrom, N. J., Kaufman, J., and Huettel, S. A. (1998). Males and females use different distal cues in a virtual environment navigation task. Cogn. Brain Res. 6, 351-360. doi: 10.1016/S0926-6410(98)00002-0

Saribay, S. A., and Andersen, S. M. (2007). Are past relationships at the heart of attachment dynamics? What love has to do with it. Psychol. Inq. 18, 183-191. doi: 10.1080/10478400701512786

Schmidt, S., Nachtigall, C., Wuethrich-Martone, O., and Strauss, B. (2002). Attachment and coping with chronic disease. J. Psychosom. Res. 53, 763-773. doi: 10.1016/S0022-3999(02)00335-5

Schmidt, S., Petersen, C., and Bullinger, M. (2003). Coping with chronic disease from the perspective of children and adolescents-a conceptual framework and its implications for participation. Child Care Health Dev. 29, 63-75. doi: 10.1046/j.1365-2214.2003.00309.x

Schönbrodt, F. D., and Asendorpf, J. B. (2010). Transference of Relationship Qualities to a Virtual World: Regulation of Behavior to a Virtual Spouse. Dissertation, Humboldt-Universität zu Berlin, Berlin.

Schönbrodt, F. D., and Asendorpf, J. B. (2011). Virtual social environments as a tool for psychological assessment: dynamics of interaction with a virtual spouse. Psychol. Assess. 23, 7-17. doi: 10.1037/a0021049

Schönbrodt, F. D., and Asendorpf, J. B. (2012). Attachment dynamics in a virtual world. J. Pers. 80, 429-463. doi: 10.1111/j.1467-6494.2011.00736.x

Shapiro, L. (2007). The embodied cognition research programme. Philos. Compass 2, 338-346. doi: 10.1016/j.cognition.2014.02.001

Shute, V. J. (2009). Simply assessment. Int. J. Learn. Media 1, 1-11. doi: 10.1162/ ijlm.2009.0014

Shute, V. J., and Ke, F. (2012). "Games, learning, and assessment," in Assessment in Game-based Learning, eds D. Ifenthaler, D. Eseryel, and X. Ge (New York, NY: Springer), 43-58. doi: 10.1007/978-1-4614-3546-4_4

Shute, V. J., Ventura, M., and Kim, Y. J. (2013). Assessment and learning of qualitative physics in newton's playground. J. Educ. Res. 106, 423-430. doi: 10.1080/00220671.2013.832970

Skalski, P., and Tamborini, R. (2007). The role of social presence in interactive agent-based persuasion. Media Psychol. 10, 385-413. doi: 10.1080/ 15213260701533102

Slater, M. (2009). Place illusion and plausibility can lead to realistic behaviour in immersive virtual environments. Philos. Trans. R. Soc. B Biol. Sci. 364, 3549-3557. doi: 10.1098/rstb.2009.0138

Sroufe, L. A. (2005). Attachment and development: a prospective, longitudinal study from birth to adulthood. Attach. Hum. Dev. 7, 349-367. doi: 10.1080/ 14616730500365928

Sroufe, L. A., Egeland, B., Carlson, E. A., and Collins, W. A. (2009). The Development of the Person: The Minnesota Study of Risk and Adaptation from Birth to Adulthood. New York, NY: Guilford Press.

Steele, M., Steele, H., Woolgar, M., Yabsley, S., Fonagy, P., Johnson, D., et al. (2003). "An attachment perspective on children's emotion narratives: links across generations," in Revealing the Inner Worlds of Young Children, eds R. Emde, D. Wolf, and D. Oppenheim (Oxford: Oxford University Press), 163-181.

Stern, D. N. (1985). The Interpersonal World of the Infant. A View from Psychoanalysis and Developmental Psychology. New York, NY: Basic Books.

Sundar, S. S., Xu, Q., and Bellur, S. (2010). "Designing interactivity in media interfaces: a communications perspective," in Proceedings of the SIGCHI Conference on Human Factors in Computing Systems, (New York, NY: ACM), 2247-2256. doi: 10.1145/1753326.1753666

Symons, D. K., Adams, S., and Smith, K. H. (2015). Adult attachment style and caregiver attitudes after raising a virtual child. J. Soc. Pers. Relationsh. 33, 1054-1069. doi: 10.1177/0265407515616710

Tarr, M. J., and Warren, W. H. (2002). Virtual reality in behavioral neuroscience and beyond. Nat. Neurosci. 5, 1089-1092. doi: 10.1038/nn948

Tronick, E. Z., and Gianino, A. F. (1986). The transmission of maternal disturbance to the infant. New Dir. Child Dev. 1986, 5-11. doi: 10.1002/cd.23219863403

Waters, E., Weinfield, N. S., and Hamilton, C. E. (2000). The stability of attachment security from infancy to adolescence and early adulthood: general discussion. Child Dev. 71, 703-706. doi: 10.1111/1467-8624.00179

Weinfield, N. S., Whaley, G. J., and Egeland, B. (2004). Continuity, discontinuity, and coherence in attachment from infancy to late adolescence: sequelae of organization and disorganization. Attach. Hum. Dev. 6, 73-97. doi: 10.1080/ 14616730310001659566 
Wilson, M. (2002). Six views of embodied cognition. Psychon. Bull. Rev. 9, 625-636. doi: $10.3758 / \mathrm{BF} 03196322$

Wrzesien, M., Alcañiz, M., Botella, C., Burkhardt, J. M., Lopez, J. B., and Ortega, A. R. (2014). "A pilot evaluation of a therapeutic game applied to small animal phobia treatment," in Proceedings of the International Conference on Serious Games Development and Applications, (Cham: Springer International Publishing), 10-20. doi: 10.1007/978-3-31911623-5_2

Yee, N., and Bailenson, J. (2007). The proteus effect: the effect of transformed selfrepresentation on behavior. Hum. Commun. Res. 33, 271-290. doi: 10.1111/j. 1468-2958.2007.00299.x
Conflict of Interest Statement: The authors declare that the research was conducted in the absence of any commercial or financial relationships that could be construed as a potential conflict of interest.

Copyright $\odot 2017$ Chicchi Giglioli, Pravettoni, Sutil Martín, Parra and Raya. This is an open-access article distributed under the terms of the Creative Commons Attribution License (CC BY). The use, distribution or reproduction in other forums is permitted, provided the original author(s) or licensor are credited and that the original publication in this journal is cited, in accordance with accepted academic practice. No use, distribution or reproduction is permitted which does not comply with these terms. 